\title{
Transapical mitral replacement with anterior leaflet splitting: A novel technique to avoid left ventricular outflow tract obstruction
}

Richard Lee, MD, MBA, Dawn S. Hui, MD, Tarek A. Helmy, MD, and Michael J. Lim, MD, FACC, FSCAI, St Louis, Mo

From the Center for Comprehensive Cardiovascular Care, Saint Louis University, St Louis, Mo.

Disclosure: Authors have nothing to disclose with regard to commercial support.

Received for publication July 20, 2017; revisions received Sept 28, 2017; accepted for publication Oct 20, 2017; available ahead of print Dec 2, 2017.

Address for reprints: Richard Lee, MD, MBA, 3635 Vista Ave, DT 13th Floor, St Louis, MO 63110 (E-mail: rlee@slu.edu).

J Thorac Cardiovasc Surg 2018;155:e95-8

$0022-5223 / \$ 36.00$

Copyright (c) 2017 by The American Association for Thoracic Surgery

https://doi.org/10.1016/j.jtcvs.2017.10.059

- Video clip is available online.

For high-risk patients with mitral disease, transapical mitral valve replacement (TAMVR) is a therapeutic option. ${ }^{1} \mathrm{~A}$ known complication of TAMVR, however, left ventricular outflow tract (LVOT) obstruction (LVOTO), occurs in as

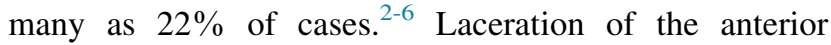
mitral leaflet (AML) to prevent this complication has been described. ${ }^{7}$ We report a novel technique that uses transapical retrograde AML splitting to prevent LVOTO.

\section{CLINICAL SUMMARY}

An 81-year-old man with previous coronary artery bypass grafting and mitral repair, chronic kidney disease, pulmonary hypertension, and atrial fibrillation was seen with New York Heart Association functional class III to IV symptoms. Echocardiography demonstrated previous mitral repair with a posterior band, nonfunctional posterior leaflet, and $1.5-\mathrm{cm}$ anteriorization of the band. Mitral regurgitation was $4+$ (vena contracta, $2-3 \times 20 \mathrm{~mm}$; area, $40 \mathrm{~mm}^{2}$; effective regurgitant fraction, $58 \%$ ). Echocardiographic analysis showed that the patient had a probable 29-mm annuloplasty band and borderline mitral stenosis (valve area, $2.6 \mathrm{~cm}^{2}$ by planimetry; mean gradient, $3.7 \mathrm{~mm} \mathrm{Hg}$ ). Anterior mitral length was $28 \mathrm{~mm}$; the aorto mitral annular (AMA) angle was $110^{\circ}$; and the LVOT diameter was $2.3 \mathrm{~cm}$. Other findings included a left ventricular ejection fraction of $50 \%$, moderate functional tricuspid regurgitation, and a right ventricular systolic pressure of $44 \mathrm{~mm} \mathrm{Hg}$. Angiography demonstrated a patent left internal

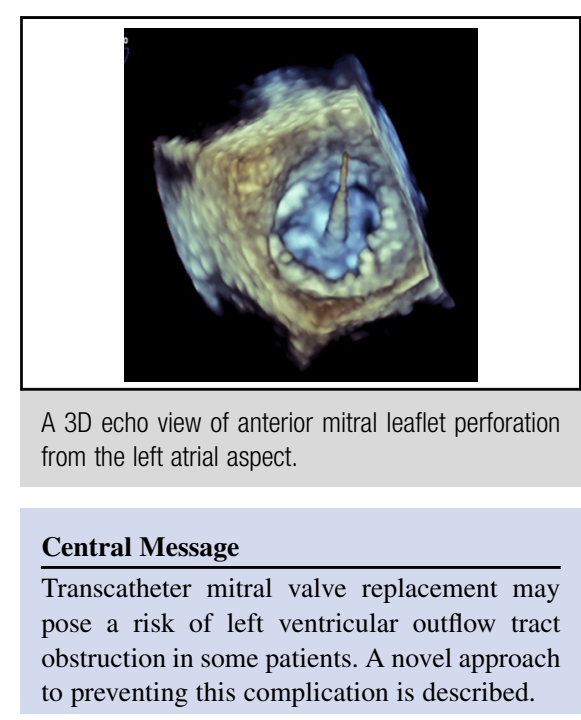

See Editorial Commentary page e99.

thoracic artery-left anterior descending coronary artery graft, occluded vein grafts, and collateralization to the right coronary artery and circumflex coronary artery territories. The Society of Thoracic Surgeons predicted risk of operative mortality was $14.5 \%$.

\section{TECHNIQUE}

After double-lumen endotracheal intubation, femoral vessels were cannulated with $6 \mathrm{~F}$ sheaths, and the artery was prepared with a preclosure device. Transthoracic ultrasonography demonstrated the optimal intercostal space for left ventricular apex access. The left lung was deflated, and a 4th intercostal minithoracotomy incision was made. The apex was indented with the surgeon's finger. Transesophageal echocardiography (TEE) demonstrated the position that would allow coaxial alignment with the AML (Video 1). Two purse-string sutures were placed at this site.

Cardiopulmonary bypass (CPB) was planned because of the anticipated acute severe coronary artery with this technique. After heparinization, femoral sheaths were exchanged for CPB cannulas. Before CPB was instituted, the apex was punctured at the center of the purse-string sutures with a long 18-gauge pericardiocentesis needle, which was advanced through the AML into the left atrium under 


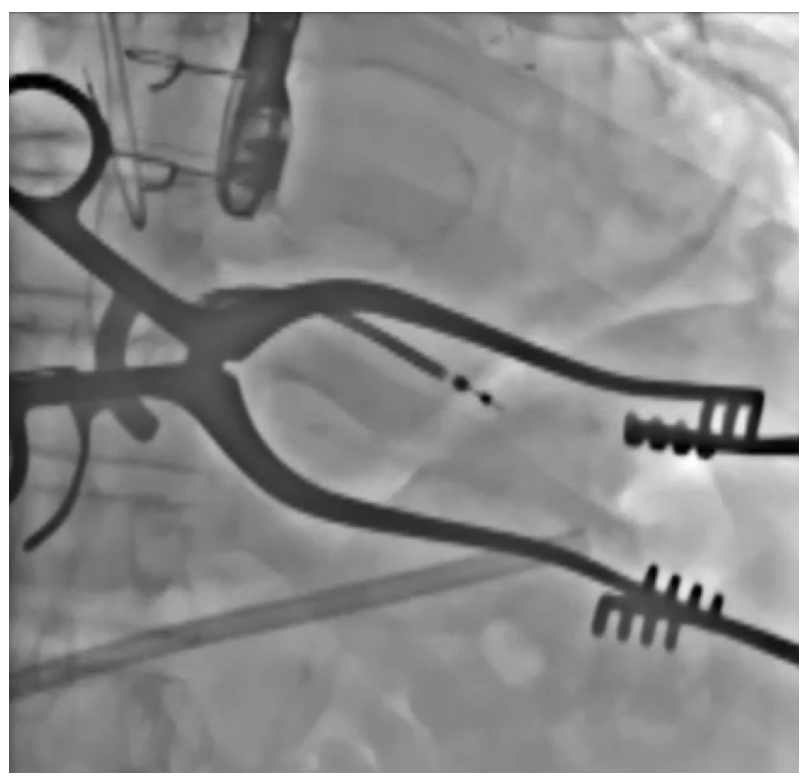

VIDEO 1. Identifying the apical site and apical puncture through the anterior mitral leaflet. Video available at: http://www.jtcvsonline.org/article/ S0022-5223(17)32381-4/fulltext.

TEE guidance (Video 1 and Figure 1). The AML puncture site was at the point midway between the base and the tip of the A2 portion (Figure 2). The tethered leaflets facilitated retrograde puncture by preventing prolapse into the atrium and providing stability.

An 0.035-inch stiff J-wire was inserted through the needle and, under TEE and fluoroscopic guidance, advanced into the right superior pulmonary vein. The apical site

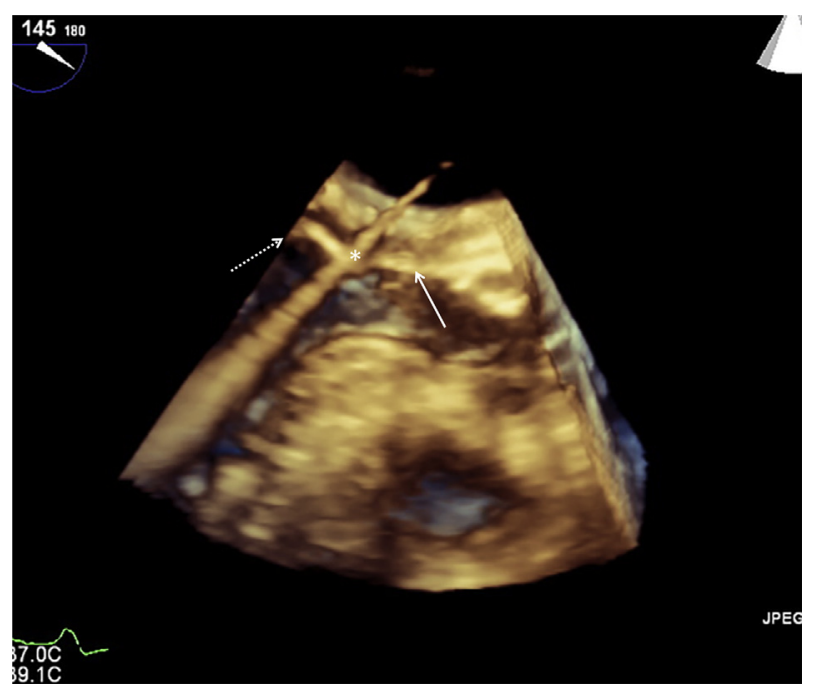

FIGURE 1. Three-dimensional echocardiographic view of the anterior mitral leaflet perforation with a long $18 \mathrm{G}$ needle. The dotted arrow indicates the free edge of the AML; the solid arrow indicates the annular attachment of the AML; and the asterisk indicates perforation at the midpoint of A2.

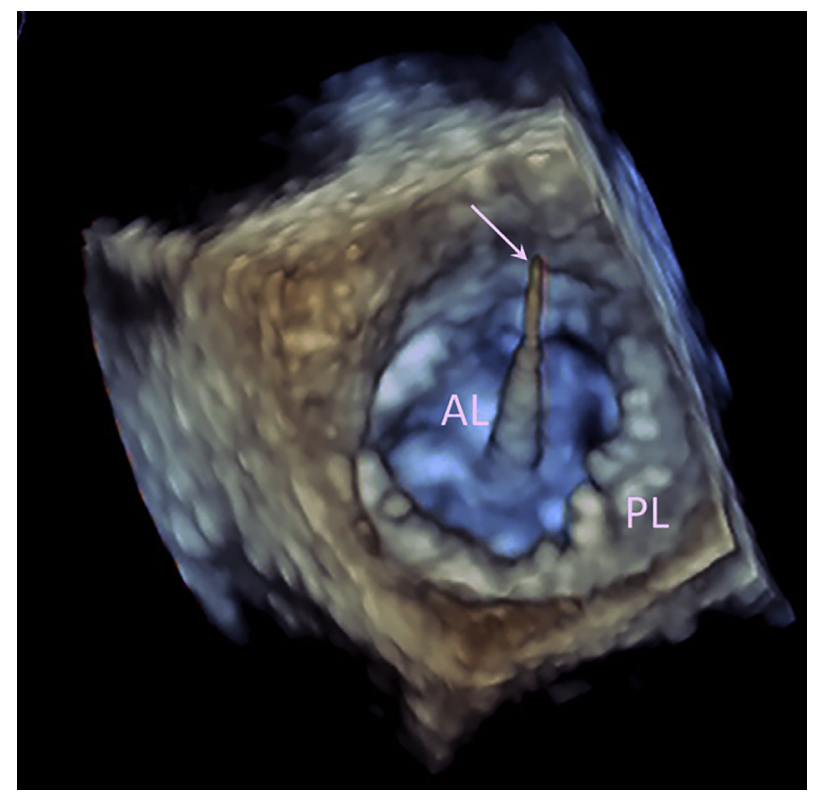

FIGURE 2. Three-dimensional echocardiographic view of leaflet perforation from the left atrial aspect. The arrow indicates the needle. $A L$, Anterior leaflet; $P L$, posterior leaflet.

was serially dilated, and the transapical delivery sheath was placed. The balloon-expandable 29-mm Sapien valve (Edwards Lifesciences, Irvine, Calif) was prepared and mounted on the delivery system.

CPB was initiated (Video 2). The coplanar view of the annulus was established under fluoroscopic guidance, with the mitral band used as a marker. A 20-mm balloon was advanced over the wire, inflated within the AML under rapid ventricular pacing (Figures 3 and 4), and deflated and withdrawn. This maneuver caused the AML to separate from the annulus (Figure 4). The hemodynamic effects of the resultant severe mitral regurgitation were mitigated by $\mathrm{CPB}$. The delivery system was advanced over the guidewire, and the valve was deployed with rapid ventricular pacing. The ventricular portion was balloon dilated with an additional $4 \mathrm{~mL}$ of contrast.

The patient was weaned from $\mathrm{CPB}$, and the valve was assessed. Intraoperative TEE demonstrated the LVOT area to be $0.7 \times 2.2 \mathrm{~cm}$ (area, $1.5 \mathrm{~cm}^{2}$ ), with a mean gradient of $7 \mathrm{~mm} \mathrm{Hg}$. The mitral valve area by planimetry was $2.5 \mathrm{~cm}^{2}$ (indexed area, $1.2 \mathrm{~cm}^{2} / \mathrm{m}^{2}$ ), and the mean transvalvular gradient was $2.8 \mathrm{~mm} \mathrm{Hg}$. There was trivial paravalvular leak, and there was no evidence of systolic anterior motion. CPB was briefly resumed for apical catheter removal; after removal, it was discontinued and the cannulas were removed. After drain placement, the incision was anesthetized and closed.

After treatment of pneumonia and adrenal insufficiency, the patient was discharged on postoperative day 10 without peripheral vascular or cerebrovascular complications. 


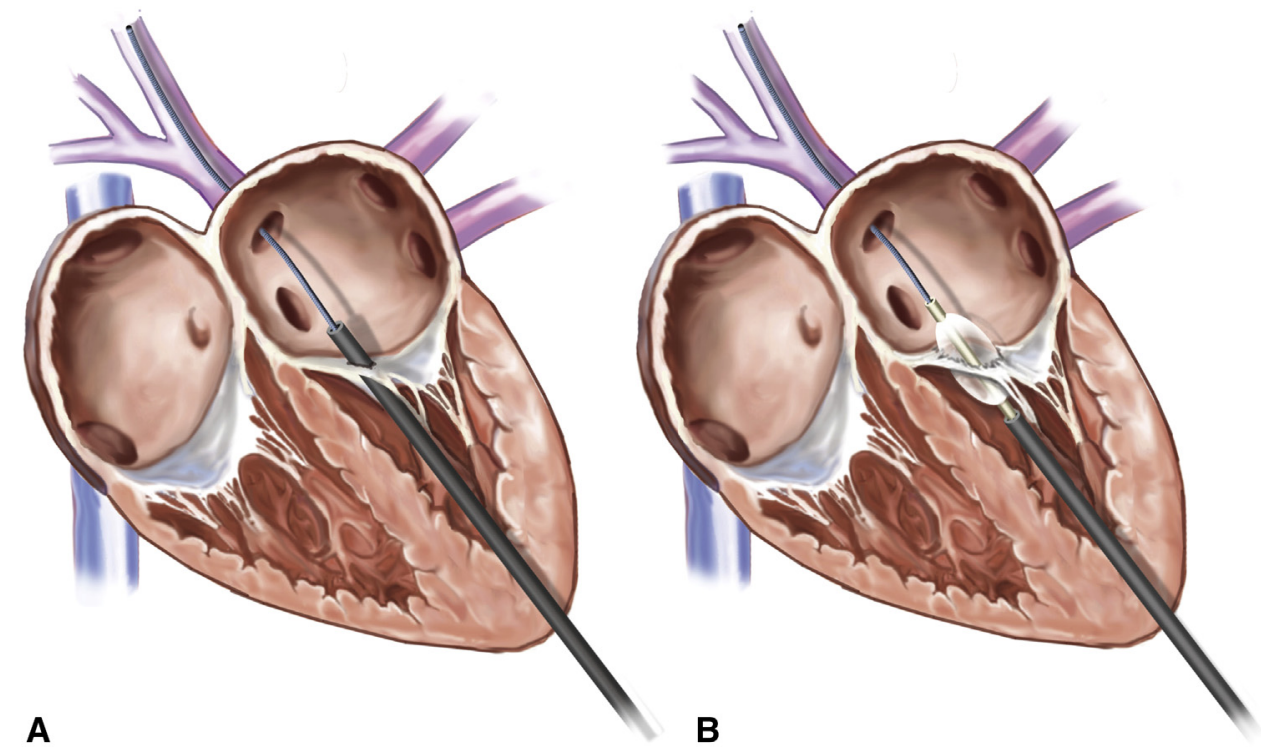

FIGURE 3. Illustration of technique. A, After the anterior leaflet is pierced with a long needle, a guidewire is advanced into the right superior pulmonary vein. $\mathrm{B}$, Balloon inflation within the anterior mitral leaflet.

Echocardiography at 1 month demonstrated a mean LVOT gradient of $3 \mathrm{~mm} \mathrm{Hg}$ and mild paravalvular leak.

\section{DISCUSSION}

Predictors of LVOTO as a complication of TAMVR have been studied in bench tests. Native structural risk factors include septal hypertrophy or bulge, small left ventricular cavity size, and AMA angle., 5,8 In patients without previous mitral replacement, the length of the anterior leaflet is also a contributing factor (Table 1). In patients with prosthetic valves, LVOTO risk may vary with the type of valve (pericardial vs porcine) and its orientation. Finally, proper positioning of the transcatheter device is also crucial, with the ideal implantation depth $80 \%$ atrial and $20 \%$ ventricular. In the case presented here, the AMA angle and predicted neovalve size (derived from existing valve dimensions) were considered to place the patient at high risk for LVOTO.

The hemodynamics of LVOTO can be significant enough to require urgent intervention. Although some have recommended open surgery as the best option, ${ }^{2}$ most patients undergoing TAMVR are high risk at baseline, making emergency surgery an unattractive option. Others suggest septal alcohol ablation as a bailout ${ }^{4}$; however, a series of 6 cases reported 2 deaths, 1 after surgical conversion and 1 of complete heart block. ${ }^{5}$ Preventive techniques are
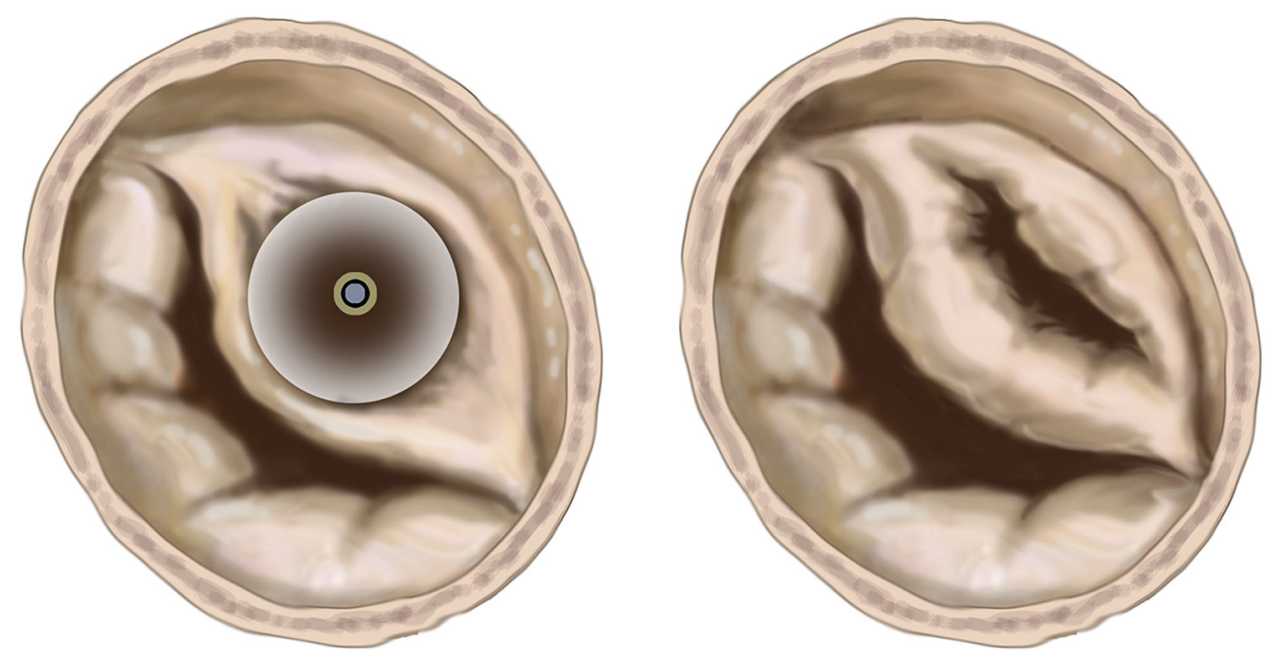

FIGURE 4. Balloon inflation (left) causes detachment of the anterior leaflet from the annulus (right), similar to the surgical chordal-sparing technique for mitral valve replacement in which the anterior leaflet is detached from the annulus. 
TABLE 1. Risk factors for left ventricular outflow tract obstruction after transapical mitral valve replacement

\begin{tabular}{ll}
\hline \multicolumn{1}{c}{ Factor } & \multicolumn{1}{c}{ Risk of LVOTO } \\
\hline Anterior mitral leaflet length & High if $>30 \mathrm{~mm}$ \\
Left ventricular cavity size & High if small \\
AMA angle & \\
$90^{\circ}$ & Complete obstruction \\
$180^{\circ}$ & No risk \\
$135^{\circ}-120^{\circ}$ & Exponential increase in degree of \\
& LVOT area reduction \\
Septal anatomy & Septal bulge or hypertrophy \\
\hline
\end{tabular}

LVOTO, Left ventricular outflow tract; $A M A$, aorto mitral annular; $L V O T$, left ventricular outflow tract.

therefore important for the successful and safe performance of TAMVR. The transcatheter-based technique described here, a modification of the laceration of the anterior mitral valve leaflet to prevent outflow track obstruction (LAMPOON) technique described by Babaliaros and colleagues, ${ }^{7}$ is conceptually similar to the surgical technique of chordal-sparing valve surgery in which the AML is detached from the annulus (Figure 4, $C$ and $D$ ). It can be used in cases in which anterior leaflet modification has previously been performed, but it should be avoided

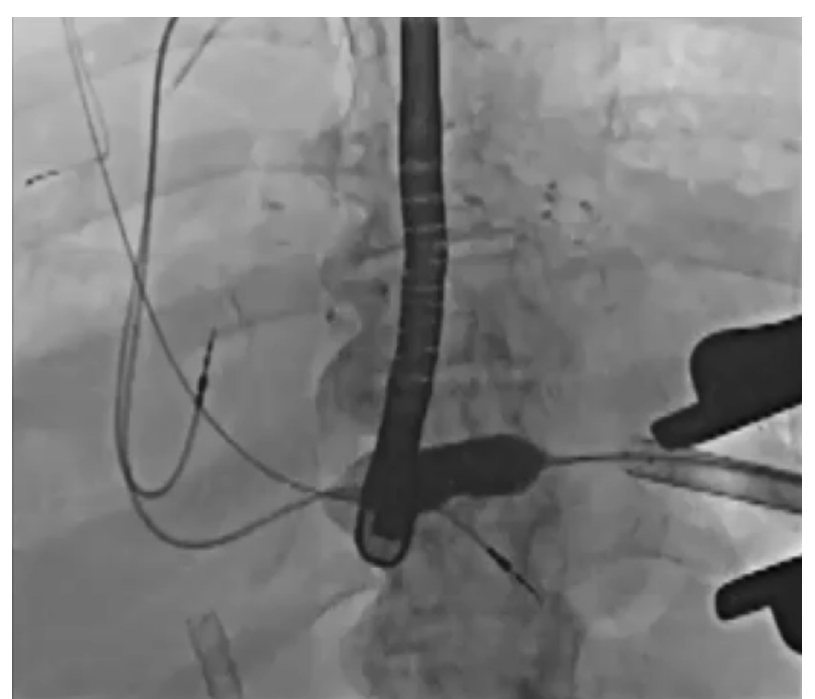

VIDEO 2. Cardiopulmonary bypass (CPB) and balloon dilation of the anterior leaflet. Video available at: http://www.jtcvsonline.org/article/ S0022-5223(17)32381-4/fulltext. in cases where a MitraClip device (Abbott; Abbott Park, IIl) has been deployed, or when there is heavy calcification involving the anterior leaflet extending to the annulus.

The initial report of the LAMPOON technique of AML laceration with an externalized electrified guidewire ${ }^{7}$ described procedural success in 5 patients. The technique presented here offers another option for LVOTO avoidance with chordal-preserving TAMVR. Although TAMVR generally can be performed with CPB on standby only, this technique does require $\mathrm{CPB}$ to mitigate the effects of acute severe mitral regurgitation. It thus avoids theoretic complications of LAMPOON (eg, injury to the aorta or aortic valve during laceration) without requiring transseptal puncture or the associated closure device.

\section{CONCLUSIONS}

This report describes a novel technique, resembling the surgical chordal-sparing technique of MV replacement, to prevent LVOTO after TAMVR. More experience is needed to verify safety and efficacy.

We thank Dr Steven C. Smart for his echocardiographic expertise and analysis and Ms Barbara Siede for the illustrations.

\section{References}

1. Puri R, Abdul-Jawad Altisent O, del Trigo M, Campelo-Parada F, Regueiro A, Barbosa Ribeiro H, et al. Transcatheter mitral valve implantation for inoperable severely calcified native mitral valve disease: a systematic review. Catheter Cardiovasc Interv. 2016;87:540-8.

2. Said SM, Pislaru S, Kotkar KD, Rihal CS, Mauermann WJ, Schaff HV, et al, Left ventricular outflow tract obstruction after transcatheter mitral valve-in-ring implantation: a word of caution. Ann Thorac Surg. 2016;102:e495-7.

3. Descoutures F, Himbert D, Maisano F, Casselman F, de Weger A, Bodea O, et al. Transcatheter valve-in-ring implantation after failure of surgical mitral repair. Eur J Cardiothorac Surg. 2013;44:e8-15.

4. Deharo P, Urena M, Himbert D, Brochet E, Rouleau F, Pinaud F, et al. Bail-out alcohol septal ablation for left ventricular outflow tract obstruction after transcatheter mitral valve replacement. JACC Cardiovasc Interv. 2016;9:e73-6.

5. Guerrero M, Wang DD, Himbert D, Urena M, Pursnani A, Kaddissi G, et al. Shortterm results of alcohol septal ablation as a bail-out strategy to treat severe left ventricular outflow tract obstruction after transcatheter mitral valve replacement in patients with severe mitral annular calcification. Catheter Cardiovasc Interv. March 7, 2017 [Epub ahead of print].

6. Latib A, Ruparelia N, Bijuklic K, De Marco F, Gatto F, Hansen L, et al. First-inman transcatheter mitral valve-in-ring implantation with a repositionable and retrievable aortic valve prosthesis. EuroIntervention. 2016;11:1148-52.

7. Babaliaros VC, Greenbaum AB, Khan JM, Rogers T, Wang DD, Eng MH, et al. Intentional percutaneous laceration of the anterior mitral leaflet to prevent outflow obstruction during transcatheter mitral valve replacement: first-in-human experience. JACC Cardiovasc Interv. 2017;10:798-809.

8. Bapat V, Pirone F, Kapetanakis S, Rajani R, Niederer S. Factors influencing left ventricular outflow tract obstruction following a mitral valve-in-valve or valvein-ring procedure, part 1. Catheter Cardiovasc Interv. 2015;86:747-60. 